\section{Effect evaluation of vitamin D level amongst patients with chronic hepatitis B}

\author{
Freshteh Osmani* \\ Infection Disease Research Center, Birjand University of Medical Sciences, Birjand, Iran
}

Vitamin D has immunomodulatory and antifibrotic properties, and therefore used for treatment of many of chronic liver disease [1]. Although there are many reports on the relationship between serum 25-hydroxyvitamin D3 levels and chronic liver diseases, but the relationship between hepatitis B virus e antigen ( $\mathrm{HBeAg}$ ) and vitamin $\mathrm{D}$ level is still unclear.

The modification and prevention of vitamin D deficiency needs an accurate illustration of the current position in each region. Vitamin D level in patients with HBV is relatively an important issue, which has been studied in many researches. As different papers published in national and international journals.

Luong and Nguyen [2], was the first researcher who was suggested the effective function of vitamin $\mathrm{D}$ in patients with HBV, in the next year, Demir, et al. [3], measured the levels of vitamin $\mathrm{D}$ in three groups as chronic hepatitis $\mathrm{B}$ (CHB) patients, naturally immunized persons and control subjects in their study, which concluded that CHB patients had lower vitamin D levels compared to two other groups [3]. In the another study, that was analyzed the association between vitamin D level and HBV in CHB patients concluded that only $19 \%$ of them had sufficient and the rest of these patients( $81 \%$ ) had vitamin D insufficiency or severe vitamin D deficiency. It was shown that lower serum vitamin D3 levels in CHB patients influence to mortality risk in hepatitis virus [4]. In another attempt, that was conducted by Schiller [4], deficiency of vitamin D in patients with CHB was confirmed [5]. Also, in one other study, the levels of vitamin D were analyzed for 128 CHB patients, including positive and negative hepatitis B virus e antigen (HBeAg) [6]. Accordingly, they concluded that serum vitamin D3 levels in patients with CHB were significantly lower than control group. Thus, in patients with positive $\mathrm{HBeAg}$, this deficiency was more intensive than negative $\mathrm{HBeAg}$. In general, lower levels of vitamin $\mathrm{D}$ in patients with $\mathrm{HBeAg}$ have been investigated indifferent studies [7].

\author{
More Information \\ *Address for Correspondence: Freshteh Osmani, \\ Infection Disease Research Center, Birjand \\ University of Medical Sciences, Birjand, Iran, \\ Tel: 0 98-09151637653; \\ Email:dr.osmani68@gmail.com; \\ f.osmani@modares.ac.ir \\ Submitted: 25 November 2019 \\ Approved: 02 December 2019 \\ Published: 03 December 2019 \\ How to cite this article: Osmani F. Effect \\ evaluation of vitamin $D$ level amongst patients \\ with chronic hepatitis B. Arch Pathol Clin Res. \\ 2019; 3: 020-021. \\ DOI: dx.doi.org/10.29328/journal.apcr.1001014 \\ ORCiD: orcid.org/0000-0002-6112-7131
}

Copyright: (c) 2019 Osmani F. This is an open access article distributed under the Creative Commons Attribution License, which permits unrestricted use, distribution, and reproduction in any medium, provided the original work is properly cited.

Keywords: Vitamin D level; Chronic HBV

(D) Check for updates

(1) OPEn ACCESS

Moreover, younger aged was associated relatively with low levels of vitamin D, and also normal alanine transaminase (ALT) was associated with high levels of vitamin D. Generally, most of studies have suggested lower serum 25-OH vitamin D3 levels among chronically infected patients with closely and negatively association.

Furthermore, lower vitamin D levels in negative HBeAg compared with positive HBeAg patients was studies in limited researches. It is understood that levels of vitamin D may have decreased in CHB patients. Almost in all of studies, it can be found that vitamin D levels were analyzed in patients with chronically infected. In the other hand, in the most of published studies conducted in Iran's population, the prevalence rate of vitamin D deficiency varied from $2.5 \%$ to $98 \%$ in different regions based on geographical regions, generally, according to present national reports; the vitamin D content is low in the Iranian diet $[8,9]$.

Despite the potential health benefits of vitamin D supplementation, drug-vitamin D interactions is rarely considered. Atorvastatin appears to increase 25 (OH)D concentrations, whereas concurrent vitamin D supplentation decreases concentrations of atorvastatin. Use of thiazide diuretics in combination with calcium and vitamin D supplements may cause hypercalcemia in the elderly or those with compromised renal function or hyperparathyroidism [10]. 
The fact is that some potential confounders may influence vitamin D serum levels (sunlight exposure, use of medications or osteoporosis prevalence), although all patients collected the blood in the same season of the year. Also, some drugs used for diabetes, for reducing cholesterol or diuretics may interfere lowering serum levels of vitamin D [11,12].

Although, for determination of vitamin D deficiency or insufficiency, as the biomarker of CHB, new designed studies may be required to understand the real association of vitamin D levels and HBV associated factors. Also, future studies should be proven the possible causal relationship between vitamin D Metabolism and HBV replication that can be attractive and offer therapeutic opportunities for the treatment of chronic hepatitis B.

\section{References}

1. Kitson MT, Roberts SK. D-livering the message: the importance of vitamin D status in chronic liver disease. J Hepatol. 2012; 57: 897-909. PubMed: https://www.ncbi.nlm.nih.gov/pubmed/22634121

2. Luong K, Nguyen LT. Theoretical basis of a beneficial role for vitamin D in viral hepatitis. World J Gastroenterol. 2012; 18: 5338-5350. PubMed: https://www.ncbi.nlm.nih.gov/pubmed/23082050

3. Demir C, Demir M. Vitamin D levels in patients with chronic hepatitis $B$ virus infection and naturally immunized individuals. Int Med Ins J. 2013; $1: 2$.

4. Schiller A, Timar R, Siriopol D, Timar B, Bob F, et al. Hepatitis B and C virus infection in the hemodialysis population from three romanian regions. Nephron. 2015; 129: 202-208.

PubMed: https://www.ncbi.nlm.nih.gov/pubmed/25765861
5. Azarkar G, Doosti Z, Osmani F, Ziaee M. Analysis Of Risk Factors For Nonalcoholic Fatty-Liver Disease In Hepatitis B Virus Infection: A Case-Control Study. Hepat Med. 2019; 11: 153-158.

PubMed: https://www.ncbi.nlm.nih.gov/pubmed/31749640

6. Wong $\mathrm{GL}, \mathrm{Chan} \mathrm{HL}$, Chan $\mathrm{HY}$, Tse $\mathrm{CH}$, Chim AM, et al. Adverse effects of vitamin $D$ deficiency on outcomes of patients with chronic hepatitis B. Clin Gastroenterol Hepatol. 2015; 13: 783-790.

PubMed: https://www.ncbi.nlm.nih.gov/pubmed/25445773

7. ChenEQ,BaiL,ZhouTY,FeM,Zhang DM, TangH. Sustained suppression of viral replication in improving vitamin $D$ serum concentrations in patients with chronic hepatitis B. Sci Rep. 2015; 5: 15441. PubMed: https://www.ncbi.nlm.nih.gov/pubmed/26486883

8. Chan HL, Elkhashab M, Trinh H, Tak WY, Ma X, et al. Association of baseline vitamin $D$ levels with clinical parameters and treatment outcomes in chronic hepatitis B. J Hepatol. 2015; 63: 1086-1092. PubMed: https://www.ncbi.nlm.nih.gov/pubmed/26143444

9. Brooke OG, Brown IR, Bone CD, Carter ND, Cleeve HJ, et al. Vitamin D supplements in pregnant Asian women: Effects on calcium status and fetal growth. Br Med J. 1980; 280: 751-754.

PubMed: https://www.ncbi.nlm.nih.gov/pubmed/6989438

10. Robien K, Oppeneer SJ, Kelly JA, Hamilton Reeves JM. Drug-vitamin D interactions: a systematic review of the literature. Nutr Clin Pract. 2013; 28: 194-208.

PubMed: https://www.ncbi.nlm.nih.gov/pubmed/23307906

11. Maghbooli Z, Hossein-Nezhad A, Shafaei AR, Karimi F, Madani FS, et al. Vitamin $D$ status in mothers and their newborns in Iran. BMC Pregnancy Childbirth.2007; 7: 1.

PubMed: https://www.ncbi.nlm.nih.gov/pubmed/17295904

12. Chan HL, Elkhashab M, Trinh H, Tak WY, Ma X, Chuang WL, et al. Association of baseline vitamin $D$ levels with clinical parameters and treatment treatment outcomes in chronic hepatitis B. J Hepatol. 2015; 63: 1086-1092.

PubMed: https://www.ncbi.nlm.nih.gov/pubmed/26143444 